\title{
MULTITEMPORAL MONITORING OF KARVINA SUBSIDENCE TROUGHS USING SENTINEL-1 AND TERRASAR-X INTERFEROMETRY
}

\author{
Milan LAZECKÝ ${ }^{1)}$ *, Eva JIRÁNKOVÁ ${ }^{1)}$ and Pavel KADLEČÍK ${ }^{2,3)}$ \\ 1) VŠB-Technical University of Ostrava, 17. Listopadu 15/2172, 70833 Ostrava-Poruba, Czech Republic \\ ${ }^{2)}$ Institute of Rock Structure and Mechanics of the ASCR, v.v.i., V Holesovickach 41, 18209 Praha 8, Czech Republic \\ ${ }^{3)}$ Faculty of Science, Charles University in Prague, Albertov 6, 12843 Praha 2, Czech Republic \\ *Corresponding author's e-mail: milan.lazecky@vsb.cz
}

\begin{tabular}{l} 
ARTICLE INFO \\
\hline Article history: \\
Received 1 May 2016 \\
Accepted 18 August 2016 \\
Available online 7 September 2016 \\
\hline
\end{tabular}

\section{Keywords:}

Subsidence

SAR Interferometry

Sentinel-1

TerraSAR-X

Mining

\begin{abstract}
Satellite SAR interferometry (InSAR) allows to observe borders of subsidence troughs created in undermined areas. There is a possibility to evaluate a subsidence velocity in the accuracy of a $\mathrm{mm} /$ year for the stable reflectors of the radio signal, e.g. buildings. We apply Permanent Scatterers (PS) and Quasi-PS (QPS) techniques for monitoring of mine-caused subsidence in the Karvina area situated in the Czech part of Upper Silesian Basin. We use PS technique as effective for observation of displacements of built structures (e.g. buildings) and QPS for monitoring of spatio-temporal development of subsidence troughs. The results reveal information valuable for an identification of deviations from expected effects of mining activities on the land surface and for the infrastructure which are potentially affected by the subsidence. We perform the processing of Sentinel-1 and high resolution TerraSAR-X to find how the lower spatial resolution of Sentinel-1 SAR affects the reliability of results. The assets of these new sensors, especially the short revisit time, can overcome the basic limits of InSAR methods connected with temporal lags between available SAR images. In previous Karvina area datasets (ERS, Envisat, Alos satellites) the basic temporal step used to be around one month. During such temporal length significant changes occured in vegetation cover or in cultivated soil causing a loss of coherence of radar measurements. In addition to this, the amount of subsidence of Karvina troughs has often exceeded detection limits of the SAR systems. A significant increase of the reliability of evaluated subsidence also in areas with a moderate vegetation cover is expected with the launch of Sentinel-1B since the short-term interferograms would not be affected by a full decorrelation.
\end{abstract}

\section{INTRODUCTION}

The landscape is being largely changed by deep coal mining. When the coal seam is extracted, the overlaying layers immediately above the coal seam are allowed to collapse into the goaf. This process of sagging continues towards to Earth's surface and results in ground subsidence. The consequence of multiple mining (resulting in subsidence) in the same territory over the decades is the formation of new local natural conditions. Hydrologic and hydrogeologic regimes are especially influenced, biota must adapt to new conditions and even human settlements could disappear. These inhospitable places for living or other human activities are used for waste dumping with the goal to be usable in the future. New "anthropogenic relief" appears.

The mining region between Ostrava and Karvina cities in eastern part of Czech Republic has been actively extracting black coal for few centuries. The highest volumes of coal has been mined from period around Second World War till present and thus also ground surface changes have reached maximum in this period. Monitoring of the subsidence using geodetic methods has a long tradition in this region (Neset, 1984). In addition, present application of InSAR can reveal information about mining induced subsidence for the whole region.

Basic techniques of satellite SAR interferometry (InSAR) have been applied using ERS and Envisat data (Lazecký et al., 2012), ALOS-1 (Lazecký et al., 2012; Lazecký and Jiránková, 2013; Kadlečík et al. 2015) as well as high resolution TerraSAR-X images (Jiránková and Lazecký, 2016), setting a general overview about temporal changes in subsidence dynamics over the area since 1992. Authors state the main limitations are especially connected with the temporal decorrelation due to the seasonal influence of the dense vegetation cover in the area and a relatively high rate of subsidence, exceeding the InSAR detection limits. The same or similar conclusions are documented in other recent works. The loss of coherence above active longwall mining sites discards PS-based InSAR measurement points either using C-band, L-band or X-band SAR (Guéguen et al., 2007; Jung et al., 2007; Walter et al., 2009; Duro et al., 2013; Iannacone et al., 2015; Du et 
al., 2016). On the other hand, very good accuracy of subsidence can be achieved at the borders of a subsidence trough and/or for periods after active phase of mining, in comparison with other measurement techniques (e.g. see Wegmüller et al., 2008; Raucoules et al., 2009).

The arrival of Sentinel-1A data brings about new possibilities. The data are easily and freely accessible, the coverage is spatially large and temporally frequent, with a 12-days revisit time within the same orbital track. The moderate spatial ground resolution of around $20 \times 4 \mathrm{~m}$ (comparable to the previous Envisat), however, limits the abilities to detect local terrain deformations. Also, the phase stability is slightly lower than at TerraSAR-X instrument, as experimentally concluded by (Marinkovic et al., 2015), showing higher standard deviation of estimations using Sentinel-1; this was also observed by own works, yet unpublished.

In this paper we focus on area of Mine Plant 1 (former Lazy Mine) and its surroundings where the mining is still in progress. Results of the levelling well described subsidence in previous years (Jiránková and Mučková, 2009). Studied area is an uninhabited land with considerable portion of vegetation cover including forest stands, dense grass covers and pioneering plants colonizing new bare surfaces. Present state of ground surface is the result of evolution from primary culture landscape (oriented on farming) with little portion of vegetation cover before extensive mining period to present wildly vegetated area since human abandonment because of subsidence and its consequences. We can say that the present conditions are a bit similar to some other natural landscapes in terms of integration of vegetation cover to the landscape unit. Using different InSAR techniques in our area can help to study the behaviour of radio signal in other natural areas.

For this study, data from Sentinel-1A and TerraSAR-X were used. In both cases, a descending track was selected. Incidence angles differ of $\sim 7-8^{\circ}$ between both satellites. Sentinel-1A (S1) dataset covers the period between $10 / 2014$ and $11 / 2015$ by 26 images of 12-24 days revisit time. In total, 23 TerraSAR-X (TSX) images were achieved in a 33days periodicity between 10/2013-12/2015. TSX data are of a higher ground resolution - around $3 \times 1 \mathrm{~m}$. These data were acquired for an investigation of road deformations above undermined areas in the region that is often problematic for S1 data of the lower ground resolution.

\section{EVALUATION OF NON-LINEAR SUBSIDENCE NEAR TO MINE PLANT 1, LAZY SITE}

Two main techniques were used for analysis of annual average rate of subsidence - the Permanent/Persistent Scatterers (PS) (Ferretti et al., 2000) and an adapted Small Baselines stacking based on Quasi-PS (QPS) technique (Perissin et al., 2007). Both techniques promise a high accuracy evaluating a linear trend of subsidence, relied on expected submillimeter sensitivity of Sentinel-1 data (Rucci et al., 2012).

The difference between both PS and QPS-based stacking technique is demonstrated in Figure 1, showing subsidence movements in the neighbourhood of Mine Plant 1 of Lazy site, Orlova. Within last years, mining activity and thus (subsequent) subsidence rate varied - the mining is performed seasonally (OKD, 2015). The PS estimation of deformation is represented by points. Their colour represents a mean estimated velocity in the Sentinel-1 (S1) satellite line-of-sight (LOS) direction that is inclined for $\sim 35^{\circ}$ from nadir. The whole data series of $\sim 1$ year were used for the estimation. It is possible to visualize time series of the estimated deformation of every PS point as visible in the upper plot in Figure 1. With appropriate number of images, the PS results are highly reliable as demonstrated by numerous works (Crosetto et al., 2016).

The majority of the observed area is covered by vegetation causing (as well as the snow cover) an irreversible decorrelation in PS InSAR analysis since it is using interferograms created by combining images in also relatively long temporal distance/baselines. In order to extract information also from such vegetated areas, only selected images taken

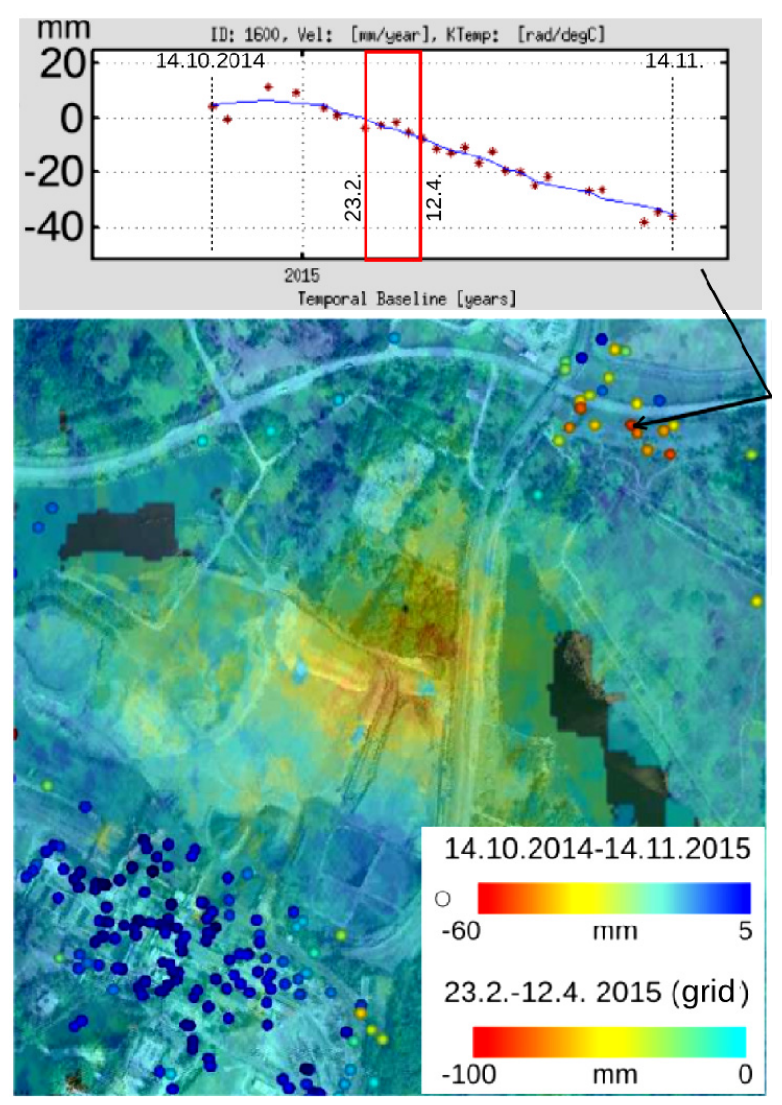

Fig. 1 Subsidence monitoring results over Mine Plant 1, Lazy site using Sentinel-1A data processed using PS InSAR (points) and stacking based on Quasi-PS InSAR (grid). 
in spring and autumn times (low vegetation leaves cover and snow-free periods) can be used for the QPS analysis. The QPS approach is introducing interferogram weighting based on overall spatial coherence. This way a linear deformation trend can be satisfactorily evaluated also in areas coherent only within a limited number of input interferograms. For the analysis visualized in Figure 1, only a subset of 5 images between $23^{\text {rd }}$ February - $12^{\text {th }}$ April 2015 were combined interferometrically within a redundant connections network. The stacked mean velocity estimations of partially coherent points were interpolated into a raster showing a clear subsidence over area used to store mine tailings.

Additionally, the non-linearity of subsidence in the area can be monitored based on comparison of differential interferograms. Due to dense vegetation cover, only springtime interferograms showed a high spatial coherence and could be reliably unwrapped. Figure 2 reveals annual changes in the location. Upper contour image comes from an unwrapped 11-day interferogram from March 2014 (TSX) while the lower image is based on unwrapped 12-day interferogram from March 2015 (S1). The mining activity in this particular area has been described in (Jiránková and Lazecký, 2016). Please note that after unwrapping, the measured values are both comparable in metric units, however the absolute value of estimated vertical movement would slightly differ due to different look angles of TSX and S1 (will be used later in the text).

\section{COMPARISON WITH LEVELLING DATA AT MINE PLANT 1, LAZY SITE - BLOCK 9}

Location of Block 9 in Mine Plant 1 is one of the multi-seam deposit of Ostrava-Karvina district. Subsidence during the decay phase of mining effects is evaluated. The end of mining activity of the last major coal face 140906 is dated to $14^{\text {th }}$ July 2012. The other nearest coalface 140908-2 has been extracted until $1^{\text {st }}$ February 2013 but its influence is not expected in this area due to its small size and far distance (Jirankova, 2016). It is expected that during the decay period of subsidence, approx. $15 \%$ of the trough would subside. Between $24^{\text {th }}$ October 2012 and $26^{\text {th }}$ September 2015 , there was $450 \mathrm{~mm}$ of subsidence measured. This corresponds to $10 \%$ of the total expected subsidence due to mining in the seam 40 in the location (OKD, 2015). The layout plan of coalfaces over the area of interest is depicted in Figure 3.

The subsidence has been evaluated from levelling of points in a linear profile over Lazecka road. The standard deviation of measured subsidence was evaluated based on kilometric errors estimated from each measurement. The difference between standard deviation of height measurements and the first reference measurement is between 1.9-2.4 mm.

Only three measurements were performed during the time period covered by Sentinel-1A and

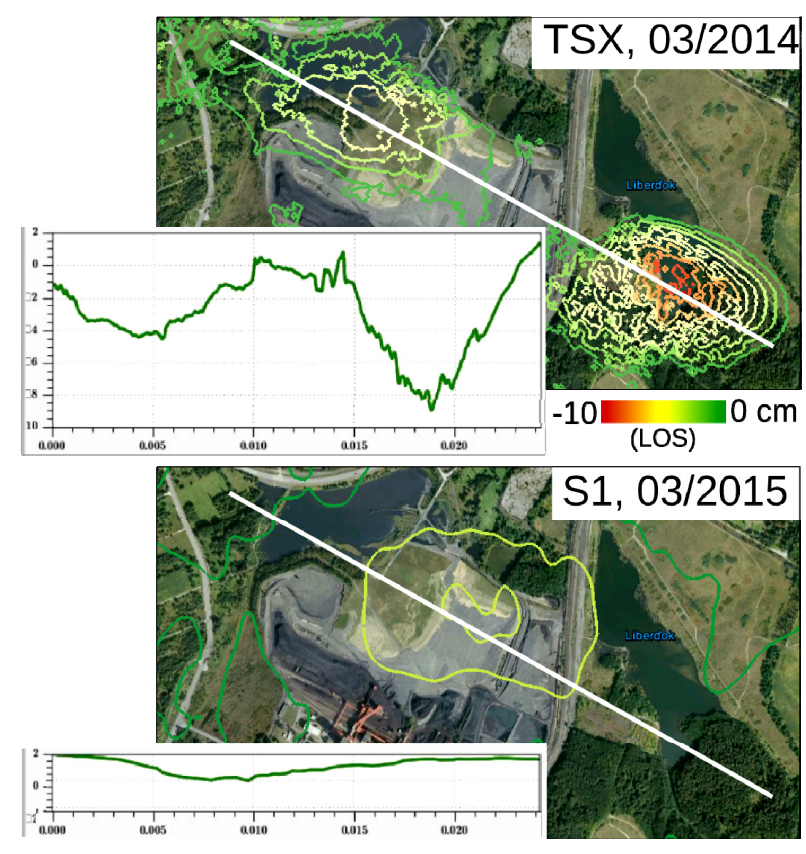

Fig. 2 Contours based on unwrapped differential 1112 days interferograms of March 2014 (TerraSAR-X, upper) and March 2015 (Sentinel-1A, lower).

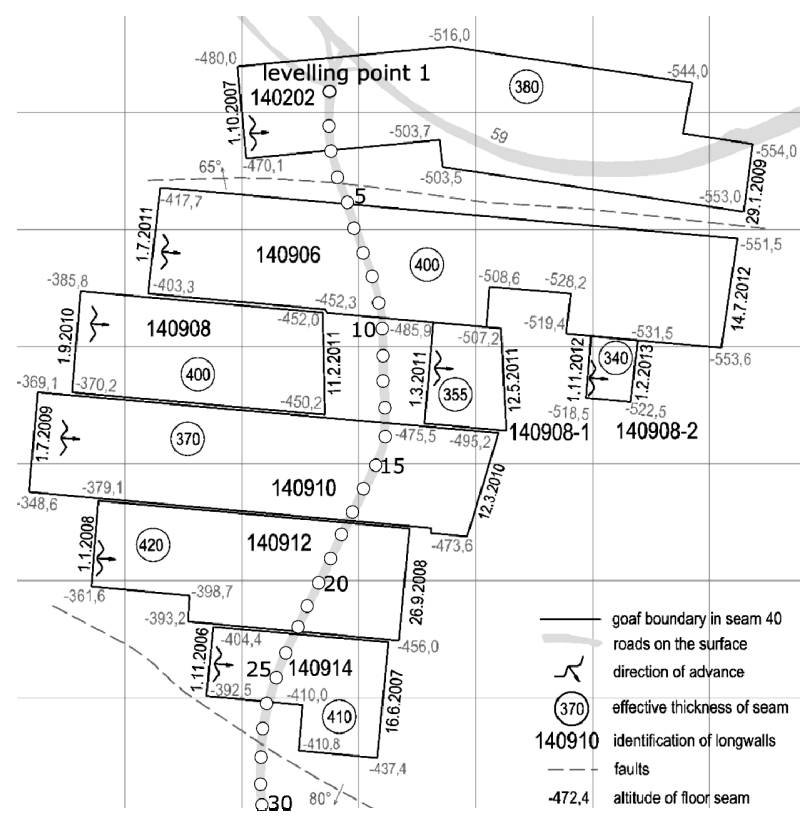

Fig. 3 Layout plan of coalfaces and miningtechnical data on extraction at Block 9. Levelling points at Lazecka road are depicted.

TerraSAR-X images. From these measurements, it is visible that between $17^{\text {th }}$ October 2014 and $21^{\text {st }}$ March 2015, a subsidence $10-18 \mathrm{~cm}$ occurred within the measured points. Such subsidence should be detectable by S1 or TSX InSAR only in assumption that the radar signal is coherent within the whole observed subsiding area. Since the area is covered by 


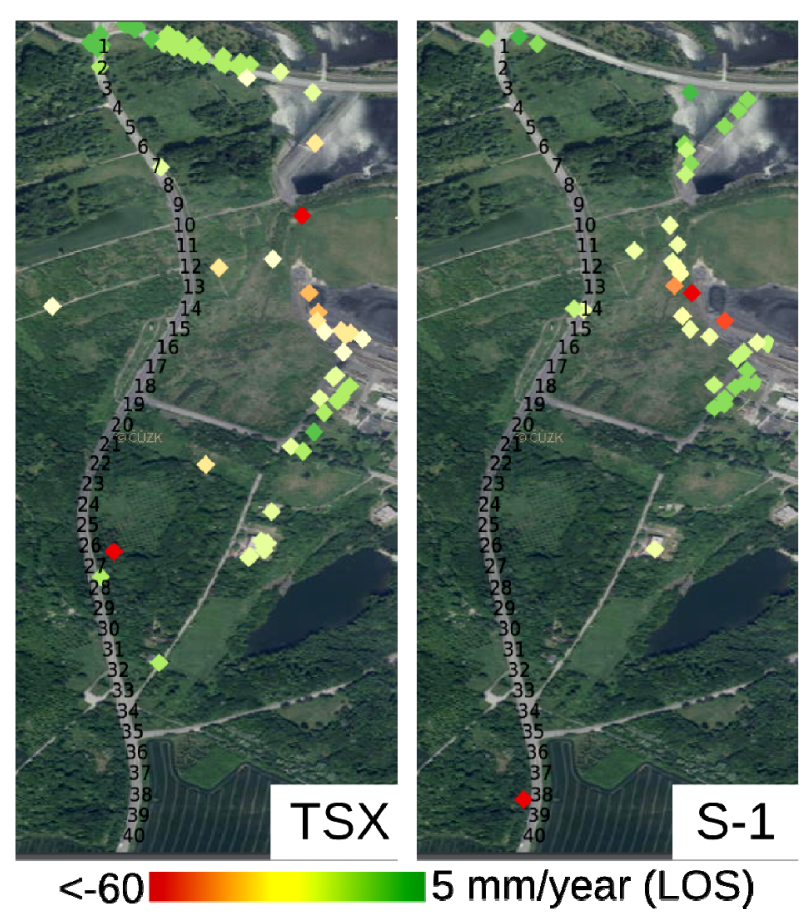

Fig. 4 PS processing results of Lazecka road area from TerraSAR-X (left) and Sentinel-1A (right). The selected points showed a temporal coherence over 0.7. Numbered points conform with established levelling measurement line.

vegetation that decorrelates the radar signal, only a small number of PS points could be used for the estimation. These points conform with the reflection from non-vegetated areas, i.e. from mine buildings or from the road Lazecka surface, as is visible in the PS results in Figure 4. In this figure only moderately high coherent points are shown. From them it is observable that both datasets are estimating a similar behaviour.

The high resolution of TSX allows a higher number of points (e.g. the road on the North in Figure 4) to be evaluated, however the shorter wavelength is more affected by vegetation and the larger time difference between available images (socalled temporal baselines) cause the result more prone to have an overall noise character. It should be noted that for this work, only images of 33-days temporal baseline were available, while TSX can offer data from even 11 days revisit time - the only 11-days pair from March 2014 showed a high overall coherence as has been already shown in Figure 2.

The high frequency of S1 acquisitions should overcome problems due to temporal decorrelation (either due to vegetation or the fast subsidence) in InSAR methods based on short baselines. The larger dataset should allow detecting a faster subsidence and proper estimation of errors in the PS technique, however the number of evaluable points is decreased due to a lower resolution. Reflection from a road is generally low since the radio signal is reflected away from the satellite. Also, the observed Lazecka road is rather narrow (around $13 \mathrm{~m}$ wide) and surrounded by high deciduous trees causing a reflection of the radar signal from their leaves. Since the pixels of S1 images have a lower ground resolution of around $20 \times 4 \mathrm{~m}$, the reflected signal is influenced by a mixture of road and leaves reflection in most cases. Therefore only a very few pixels could be used for a reliable PS estimation. In such case it is not possible to reliably evaluate a subsidence that exceeds reliable phase unwrapping limits, that are generally a quarter of the radar wavelength per interferogram (Hanssen, 2001).

In case of Sentinel-1A with the wavelength of $\sim 5.6 \mathrm{~cm}$ and the incidence angle $\sim 35.4^{\circ}$ from nadir, the reliability limit for vertical measurements is approx. $1.7 \mathrm{~cm}$ as achieved by a recomputation from LOS to vertical direction (Lazecký et al., 2016). This term means the maximal displacement that can be reliably identified within the wavelength and is equal to the phase value of $\pi / 4$ since this value can be unwrapped without increasing ambiguity due to phase jumps (Hanssen, 2001). Similarly, in case of TSX with the wavelength of $\sim 3.11 \mathrm{~cm}$ and the incidence angle around $27.7^{\circ}$, this limit value is less than $0.9 \mathrm{~cm}$. There was in total $8 \mathrm{~S} 1$ images and 5 TSX images between 17 October 2014 and 21 March 2015 allowing a reliable unwrapping of maximally $13.6 \mathrm{~cm}$ (S1) or $4.4 \mathrm{~cm}$ (TSX) within this period. This issue is demonstrated in Figure 5. This figure demonstrates the unwrapping limits that do not conform with the measured subsidence by levelling. However, it is also visible that during another measurement period between 21 March and 26 September 2015, the changes are low and should be detectable from both TSX and S1. Unfortunately, this period is typical for the highest vegetation growth. Surrounding deciduous trees strongly decorrelate S1 signal and affects also signal of the high resolution TSX. For following analysis, only the TSX data could be applied, dropping $\mathrm{S} 1$ due to its low resolution unsuitable in this area.

The reliability drops significantly with the PS temporal coherence coefficient (Colesanti et al., 2003). For the levelling comparison purposes in this period, also low coherent points were considered from TSX PS analysis that include a high ambiguity of the estimations. Due to lack of highly coherent estimations of PS points over the observed road, the comparison with levelling failed to prove its reliability. However, by comparison between difference of levelling measurements and estimated vertical displacements of approximately corresponding points within the levelling profile, one may find a good correspondence once SAR phase unwrapping errors are considered. This is demonstrated in Figure 6 - the estimated PS points values are replicated within the TSX wavelength jumps (wave ambiguity) distance (red dashed lines).

\section{CONCLUSIONS}

The possibilities of current monitoring of mining induced subsidence are demonstrated on TerraSAR-X 


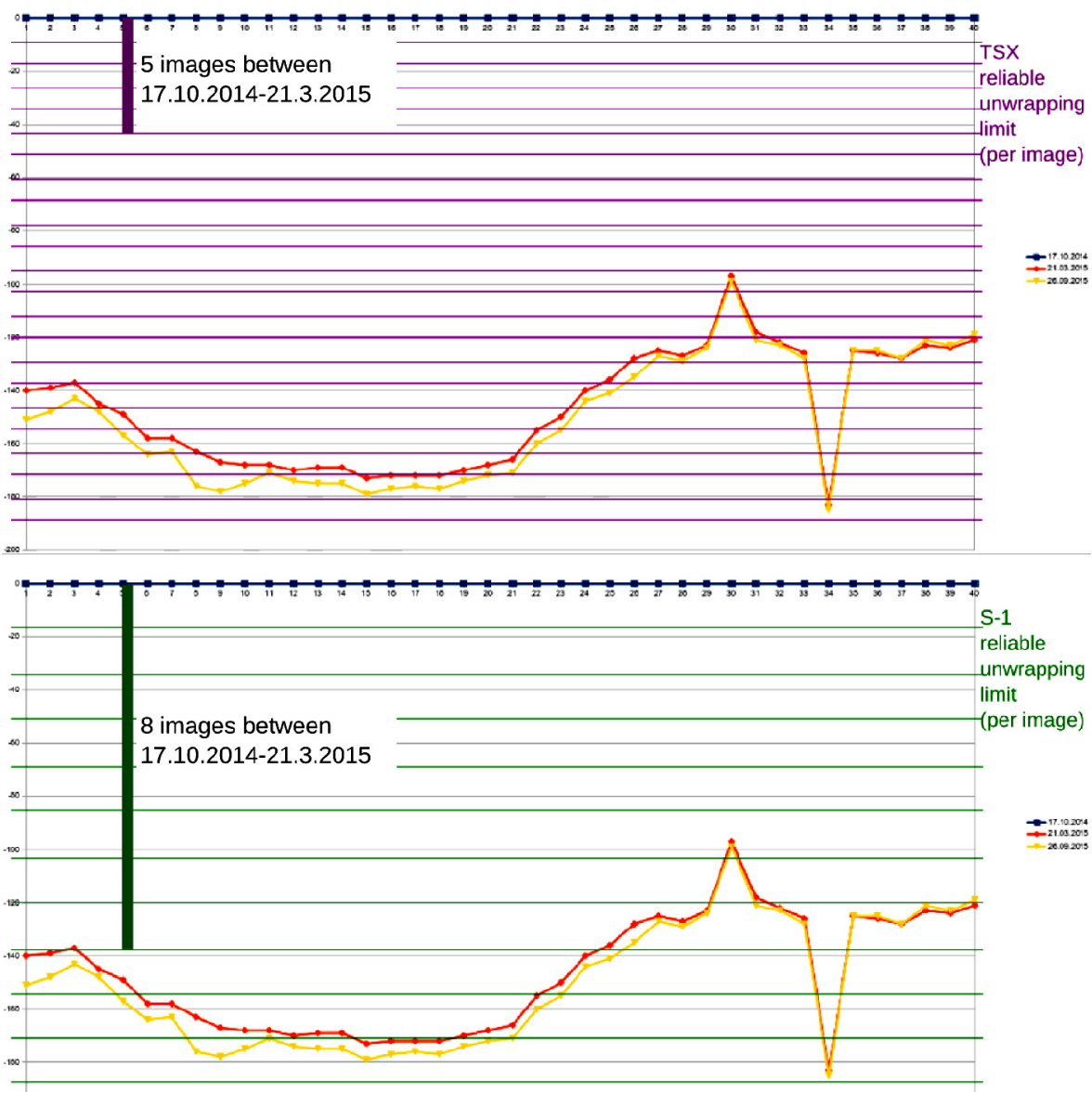

Fig. 5 Reliable unwrapping limits of TerraSAR-X (upper) and Sentinel-1 (bottom) in comparison with levelling measurements of Lazecka road between 17 October 2014 (blue, reference), 21 March 2015 (red) and 26 September 2015 (yellow).

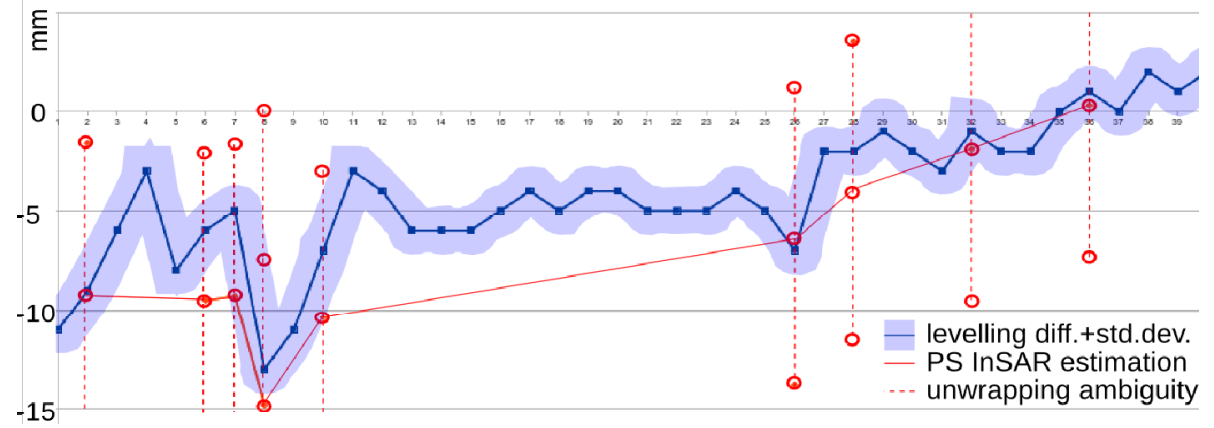

Fig. 6 Comparison levelling measurements between 21/03 and 26/09 2015 and TSX PS InSAR points in the surroundings of the levelling profile, considering phase unwrapping ambiguity.

(2013-2015) and Sentinel-1 datasets (2014-2015) within the Karvina region.

The high coherence of short-temporal springtime interferograms outlines the potential of Sentinel-1 for annual evaluation of subsidence troughs in the nonurban conditions such as Karvina mining district. The QPS-based stacking method deals well with the decorrelation sources. Due to the large coverage of Sentinel-1 data, we may relatively easily prepare reliable annual large-scale maps of springtime subsidence. A concluding example of the potential of InSAR in evaluation of short-term subsidence is demonstrated in Figure 7, based on simple QPS-based stacking of $5 \mathrm{~S} 1$ short-temporal interferograms from the springtime 2015 .

The connection of QPS approach together with PS reveals more information about non-linearity of subsidence process during a year as well as the differential interferometry does. 


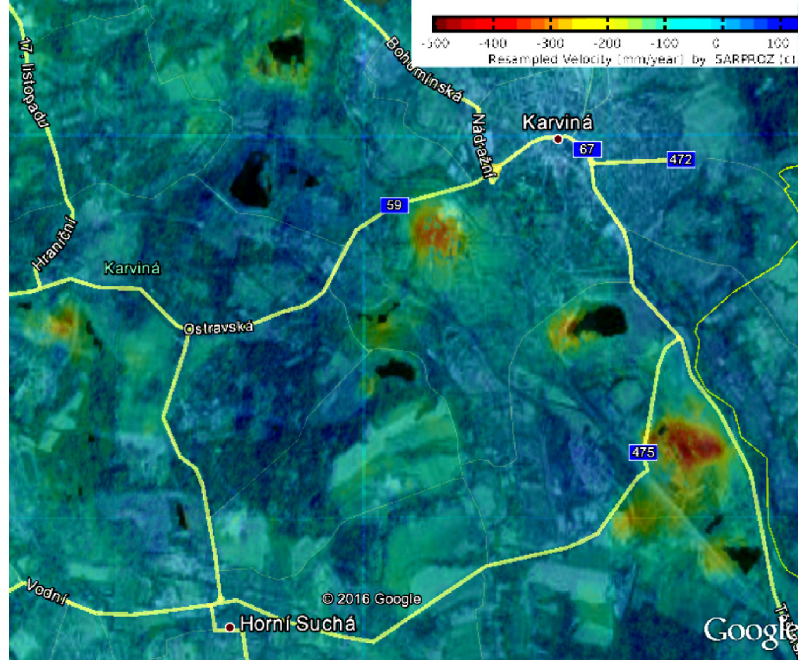

Fig. 7 Estimated annual LOS mean deformation velocity of subsidence troughs in Karvina mine areas based on processing of 5 Sentinel1 images from 2015/02/-2015/04/12 using Quasi-PS InSAR. Result is after grid interpolation.

Results of PS processing were validated with $2-\mathrm{km}$ long levelling line for decay phase of subsidence.

A comparison between application of Sentinel-1 and TerraSAR-X data available leads to several empirically observed conclusions. The lower spatial resolution of Sentinel-1 images becomes a problem in case of monitoring areas covered by dense vegetation without any dominant reflector. An example of road Lazecka shows a total decorrelation due to the vegetation while high resolution images from TerraSAR-X could at least distinguish the road itself from the surrounding forest. Yet, the estimated results were highly ambiguous due to the limited detectability of fast movements within the current TerraSAR-X dataset. It can be expected that better results would be achieved with a higher image frequency that would overcome the problem with the temporal decorrelation due to changes in vegetation cover. This great advantage can be expected from Sentinel-1B that should accompany Sentinel-1A in a constellation, lowering the revisit time to 6 days since the second half of 2016. Yet, the physical properties of applied wavelength in both S1 and TSX disallow application in densely vegetated areas, for example dense forests, with the exception of early spring time interferograms, i.e. before the growth of leaves of deciduous trees.

\section{ACKNOWLEDGMENTS}

This work was supported by The Ministry of Education, Youth and Sports from the National Programme of Sustainability (NPU II) project „IT4Innovations excellence in science - LQ1602“ and from the Large Infrastructures for Research, Experimental Development and Innovations project
„IT4Innovations National Supercomputing Center LM2015070“. This work was supported by project „Disaster management support scenarios using geoinformation technologies" No. VG20132015106 and by the "Updated project No. 35 for solution of the Moravian-Silesian Region revitalization - Complex solution of methane problems related to old mining works". TerraSAR-X data were acquired under DLR project LAN1130, (c) DLR 2015. Sentinel-1A data is provided by the courtesy of ESA, methane screening data were achieved by GG DPB Paskov. Authors are grateful to Dr. Daniele Perissin for offering usage of SARPROZ software for processing the data.

\section{REFERENCES}

Colesanti, C., Ferreti, A., Novali, F., Prati, C. and Rocca, F.: 2003, SAR monitoring of progressive and seasonal ground deformation using the permanent scatterers technique. IEEE Transactions on Geoscience and Remote Sensing, 41, 7, 1685-1701. DOI: $10.1109 /$ TGRS.2003.813278

Crosetto, M., Monserrat, O., Cuevas-González, M., Devanthéry, N. and Crippa, B.: 2016, Persistent Scatterer Interferometry: A review. ISPRS Journal of Photogrammetry and Remote Sensing, 115, 78-89. DOI: $10.1016 /$ j.isprsjprs.2015.10.011

Du, Z., Ge, L., Li, X. and Ng, A.H.: 2016, Subsidence monitoring over the Southern Coalfield, Australia using both L-Band and C-Band SAR time series analysis. Remote Sens., 8, 7, 543 .

DOI: $10.3390 / \mathrm{rs} 8070543$

Duro, J., Albiol, D., Mora, O. and Payàs, B.: 2013, Application of advanced InSAR techniques for the measurement of vertical and horizontal ground motion in longwall minings. 13th Coal Operators' Conference, University of Wollongong, The Australasian Institute of Mining and Metallurgy \& Mine Managers Association of Australia, 99-106.

Ferretti, A., Prati, C. and Rocca, F.: 2000, Nonlinear subsidence rate estimation using permanent scatterers in differential SAR interferometry. IEEE Transactions on Geoscience and Remote Sensing, 38, 5, 22022212. DOI: $10.1109 / 36.868878$

Guéguen, Y., Al Heib, M., Deffontaines, B., Fruneau, B., De Michele, M., Raucoules, D., Guise, Y. and Planchenault, J.: 2007, Residual subsidence analysis after the end of coalmine work using topometric measurement and interferometry technics: Example from Lorraine and Nord -Pas - de Calais coalmines, France. International Society for Mine Surveying, XIII International Congress, Budapest, Hungary, 24-28 September 2007, 11 pp.

Hanssen, R.F.: 2001, Radar interferometry: Data interpretation and error analysis. Dordrecht: Kluwer Academic Publishers, 275 pp.

Iannacone, J.P., Corsini, A., Berti, M., Morgan, J. and Falorni, G.: 2013, Characterization of longwall mining induced subsidence by means of automated analysis of InSAR time-series. In Lollino et al. (eds.), Engineering Geology for Society and Territory, 5, 973-977.

Jiránková, E.: 2016, Assessment of the surface subsidence after the end of mining in the area of Block 9 of Mine Plant 1. 16th International Multidisciplinary Scientific 
GeoConference Surveying Geology and Mining Ecology Management, Albena, Bulgaria, 30.6.6.7.2016, 8 pp.

Jiránková, E. and Lazecký, M.: 2016, Specifics in the formation of subsidence troughs in the Karvina part of the Ostrava-Karvina Coal District with the use of radar interferometry. Acta Geodyn. Geomater., 13, No. 3 (183), 263-269.

DOI: $10.13168 /$ AGG.2016.0008

Jiránková, E. and Mučková, J.: 2009, Data collection for development of assessment methods of firm roof failure based on mine surveying observations. GeoScience Engineering, LV (4), http://gse.vsb.cz.

Jung, H., Kim, S., Jung, H., Min, K. and Won, J.: 2007, Satellite observation of coal mining subsidence by persistent scatterer analysis. Engineering Geology, 92, Issues 1-2, 1-13. DOI: 10.1016/j.enggeo.2007.02.007

Kadlečík, P., Kajzar, V., Nekvasilová, Z., Wegmüller, U. and Doležalová, H.: 2015, Evaluation of the subsidence based on dinSAR and GPS measurements near Karviná, Czech Republic. AUC Geographica, 50, No. 1, 51-61.

Lazecký, M., Jiránková, E., Rapant, P. and Bláha, P.: 2012, Monitoring of subsidence in Karviná Mining Region using InSAR methods. International Journal of EGRSE, 2012/1, 19-40.

Online: http://www.caag.cz/egrse/2012-1/03 lazecky-r.pdf

Lazecký, M. and Jiránková, E.: 2013, Optimization of satellite InSAR techniques for monitoring of subsidence in the surroundings of Karviná Mine: Lazy Plant. Acta Geodyn. Geomater., 10, No. 1 (169), 6165. DOI: 10.13168/AGG.2013.0005

Lazecký, M., Qin, Y., Perissin, D. and Canaslan-Comut, F.: 2016, Sentinel-1 interferometry system. In the HPC Environment of IT4Innovations, GIS Ostrava 2016, 16-18 March 2016, 7 pp.

Marinkovic, P., Larsen, Y., Lauknes, T. M., Perski, Z. and Dehls, J.: 2015, Interferometric and geodetic validation of Sentinel-1 experiences from the 1st year of operation. CEOS Calibration and Validation Workshop 2015, 27-29 October, 2015, Noordwijk, http://sarcv.ceos.org/site media/media/documents/01 S1_QualityControl_CEOS-PMarinkovic-2710205.pdf
Neset, K.: 1984, Effects of undermining. SNTL, Praha, 344 pp., (in Czech).

OKD, Inc. 2015, Private communication.

Perissin, D., Ferretti, A., Piantanida, R., Piccagli, D., Prati, C., Rocca, F., Rucci, A. and de Zan, F.: 2007, Repeatpass SAR interferometry with partially coherent targets. Fringe Workshop, Frascati, 7 pp.

Raucoules, D., Bourgine, B., De Michele, M., Le Cozannet, G., Closset, L., Bremmer, C., Veldkamp, H., Tragheim, D., Bateson, L., Crosetto, M., Agudo, M. and Engdahl, M.: 2009. Validation and intercomparison of Persistent Scatterers Interferometry: PSIC4 project results. J. Appl. Geophys., 68, 3, 335-347.

DOI: $10.1016 /$ j.jappgeo.2009.02.003

Rucci, A., Ferretti, A., Monti Guarnieri, A. and Rocca, F.: 2012, Sentinel 1 SAR interferometry applications: The outlook for sub millimeter measurements, Remote Sensing of Environment, 120, 156-163. DOI: $10.1016 /$ j.rse.2011.09.030

Walter, D., Wegmüller, U, Spreckels, V., Hannemann, W. H. and Busch, W.: 2009, Interferometric monitoring of an active underground mining field with highresolution SAR sensors. Proceedings of the ISPRS Workshop, 2-5 June, Hannover, Germany, 6 pp.

Wegmüller, U., Walter, D., Spreckels, V. and Werner, C.: 2008, Evaluation of TerraSAR-X DINSAR and IPTA for ground-motion monitoring. Proc. of the 3rd TerraSAR-X Science Team Meeting, 25-26 Nov 2008, DLR, Oberpfaffenhofen, Germany. 